Prof. R. Wehner und D. Herzmann danke ich für die Durchsicht des Manuskripts. D. Rigoli hat die Zeichnungen angefertigt. Eigene experimentelle Arbeiten wurden vom Schweizerischen Nationalfonds finanziell unterstützt (Projekt Nr. 3.073.0.81 und 3.665.0.84, R. Wehner).

1. Frisch, K. von: Naturwissenschaften 35,38 (1948)

2. Frisch, K. von: Experientia 5, 142 (1949)

3. Frisch, K. von: Tanzsprache und Orientierung der Bienen. Berlin-Heidelberg-New York: Springer 1965

4. Autrum, H., Stumpf, H.: Z. Naturforsch. $5 b, 116$ (1950)

5. Vries, H. de, Spoor, A., Jielof, R.: Physica 19, 419 (1953)

6. Stockhammer, H.: Z. vergl. Physiol. 38,39 (1956)

7. Laughlin, S.B., Menzel, R., Snyder, A.W., in: Photoreceptor Optics (A.W. Snyder, R. Menzel, eds.). Berlin-Heidelberg-New York: Springer 1975

8. Goldsmith, T.H., Wehner, R.: J. Gen. Physiol. 70, 453 (1977)

9. Snyder, A.W., Menzel, R., Laughlin, S.B.: J. Comp. Physiol. 87, 99 (1973)

10. Wehner, R., Bernard, G.D., Geiger, E.: ibid. 104, 225 (1975)

11. Menzel, R., in: Photoreceptor Optics (A.W. Snyder, R. Menzel, eds.). Berlin-Heidelberg-New York: Springer 1975

12. Waterman T.H., in: Photoreception and Vision in Invertebrates (M.A. Ali, ed.). New York-London: Plenum Press 1984

13. Autrum, H., Zwehl, V. von: Z. vergl. Physiol. 48, 357 (1964)

14. Helversen, O. von: J. Comp. Physiol. 80, 439 (1972)
15. Menzel, R., et al. : ibid. 158,165 (1986)

16. Helversen, O. von, Edrich, W.: ibid. 94, 33 (1974)

17. Menzel, R., Snyder, A.W.: ibid. 88, 247 (1974)

18. Labhart, T.: ibid. 141, 19 (1980)

19. Wehner, R., Bernard, G.D.: ibid. 137, 205 (1980)

20. Wehner, R., Strasser, S.: Physiol. Entomol. 10, 337 (1985)

21. Meyer, E., Labhart, T.: Cell Tiss. Res. 216, 491 (1981)

22. Sommer, E.W.: Dissertation Univ. Zürich 1979

23. Wehner, R.: Neujahrsbl. Naturforsch. Ges. Zuerich 184, 1 (1982)

24. Waterman, T.H., in: Handbook of Sensory Physiology, Vol. VII/6B (H. Autrum, ed.). Berlin-Heidelberg-New York: Springer 1981

25. Rossel, S., Wehner, R., Lindauer, M.: J. Comp. Physiol. $125,1(1978)$

26. Rossel, S., Wehner, R.: Proc. Nat. Acad. Sci. USA 79, 4451 (1982)

27. Rossel, S., Wehner, R.: J. Comp. Physiol. A 154, 607 (1984)

28. Wehner, R., Rossel, S., in: Experimental Behavioural Ecology and Sociobiology (B. Hölldobler, M. Lindauer, eds.). Stuttgart-New York: Fischer 1985

29. Rossel, S., Wehner, R.: Nature 323, 128 (1986)

30. Kirschfeld, K.: Z. Naturforsch. 27 c, 578 (1972)

31. Rossel, S., Wehner, R.: in Vorb.

32. Rossel, S., Wehner, R.: J. Comp. Physiol. A 155, 605 (1984)

Eingegangen am 20. August 1986

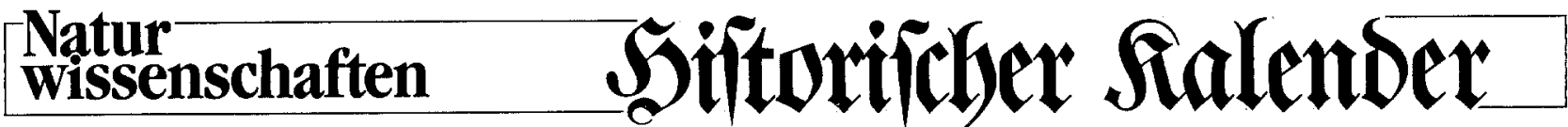

Vor 350 Jahren, am 12. Februar 1637, wurde in Amsterdam

\section{Jan Swammerdam}

geboren. Als Sohn eines wohlhabenden Apothekers war es Swammerdam möglich, die Leidener Universität zu besuchen. Dort lenkte sein Freund Reinier de Graaf (1641-1673, nach ihm wurden die Ovarienfollikel benannt) sein Interesse frühzeitig auf die Anatomie. Reisen nach Paris (1664) und Amsterdam folgte 1667 in Leiden die Promotion zum Dr. med., nach der sich Swammerdam nicht, wie sein Vater erhofft hatte, der praktizierenden Medizin, sondern der mikroskopischen Anatomie zuwandte. Daraufhin wurde ihm die väterliche finanzielle Unterstützung gestrichen, und er setzte unter schwierigen wirtschaftlichen Verhältnissen seine Forschung fort. Gegenstand waren in erster Linie die Wirbellosen, vor allem Insekten, zu denen er umfangreiches Manuskriptmaterial hinterließ (das meiste hiervon wurde erst posthum unter dem Titel ,Biblia naturae“ von H. Boerhaave (1668-1738) herausgegeben). Swammerdam befaßte sich überwiegend mit der Entwicklungsbiologie; er entwickelte zum ersten Mal klare Vorstellungen über das Wesen parasitischer Insekten und stellte eine erste Einteilung aller Insekten nach der Art ihrer Individualentwicklung auf: Insekten ohne, mit unvollkommener und mit vollkommmener Metamorphose sowie solche, die in keines dieser Schemata passen. Swammerdam starb drei Tage nach seinem 43. Geburtstag in Amsterdam. 